


\section{Professional collaboration as a key support for teachers working in challenging environments}

- Teacher collaboration is a crucial part of a teacher's professional practices. It needs to be supported in challenging learning environments, in particular, and to be reinforced for the COVID-19 crisis.

- Across the OECD, on average, one-fifth of teachers work in challenging school environments where more than $30 \%$ of students are from socio-economically disadvantaged homes.

- TALIS data show that, for some countries and economies, teachers in such schools are more likely to undertake collaborative activities with their colleagues than teachers working in schools with lower concentrations of disadvantaged students. These activities include teaching jointly in teams in the same class, observing other teachers and providing feedback, engaging in joint activities across different classes and age groups, and participating in collaborative professional learning.

- Teachers in schools with a high share of students from disadvantaged homes engage less often in the regular exchange of teaching materials with colleagues than teachers working in schools with a lower share of students from disadvantaged homes.

- TALIS finds that teacher collaboration is associated with greater innovation (measured by the use of cognitive activation practices) in the classroom and higher levels of self-efficacy and job satisfaction among teachers.

Teachers' work is multifaceted and dynamic. They frequently encounter students with different needs, such as different ability levels and learning styles, and frequently need to give students feedback or interpersonal support. The COVID-19 pandemic has posed new challenges, as teachers have had to communicate with their students, facilitate learning processes and monitor students' learning without being physically present. While teachers' interactions with their students lie at the heart of the teaching and learning process, their relationships and interactions with their colleagues constitute a key professional dimension that has also been seriously affected by the pandemic. Collaboration with colleagues allows teachers to learn from each other's expertise, share knowledge within their professional community and, ultimately, improve the instruction and support they can give to their students.

Based on the latest results from the OECD's Teaching and Learning International Survey (TALIS 2018), this Teaching in Focus brief sheds light on how collaboration among teachers constitutes a key source of professional support, especially for those teachers who work in schools with a high concentration of students from socially and economically disadvantaged backgrounds.

\section{What is TALIS?}

The Teaching and Learning International Survey (TALIS), established in 2008, is the first major international survey of teachers and school leaders on different aspects that affect student learning. It gives a voice to teachers and school leaders, allowing them to provide input into educational policy analysis and development in key areas.

The international target population for TALIS 2018 is lower secondary teachers and their school leaders in mainstream public and private schools. In each country, a representative sample of 4000 teachers and their school principals from 200 schools was randomly selected for the study. Some countries also opted to survey teachers and school leaders in primary or upper secondary schools, as well as in schools participating in the Programme for International Student Assessment (PISA). Across all survey components, approximatively 260000 teachers responded to the survey, representing more than 8 million teachers in 48 participating countries and economies.

An OECD average is estimated based on the arithmetic average of lower secondary teacher data across the 31 OECD countries and economies participating in TALIS. The report refers to the average teacher "across the OECD" as equivalent shorthand for the average teacher "across the 31 OECD countries and economies participating in TALIS".

More information is available at www.oecd.org/education/talis. 
On average across OECD countries, one-fifth of teachers work in schools where more than $30 \%$ of students are socio-economically disadvantaged - i.e. those whose homes lack the basic necessities or advantages of life, such as adequate housing, nutrition or medical care (Figure 1). Teaching in these schools is more challenging and demanding because of the need to offset lower levels of student achievement compared to schools that have a smaller proportion of students from disadvantaged backgrounds. Teachers in these schools may also face inadequate infrastructural and training resources, which shape the quality of teaching and learning taking place in these schools. In such contexts, the professional community in which teachers and school principals collaborate for various purposes can be a key means of ensuring teachers have a supportive working environment, as well as providing a mechanism to help teachers improve their practice.

Figure 1. Teachers in schools with a high concentration of students from socio-economically disadvantaged backgrounds Percentage of lower secondary teachers teaching in schools where more than $30 \%$ of students come from a socio-economically disadvantaged home ${ }^{1}$

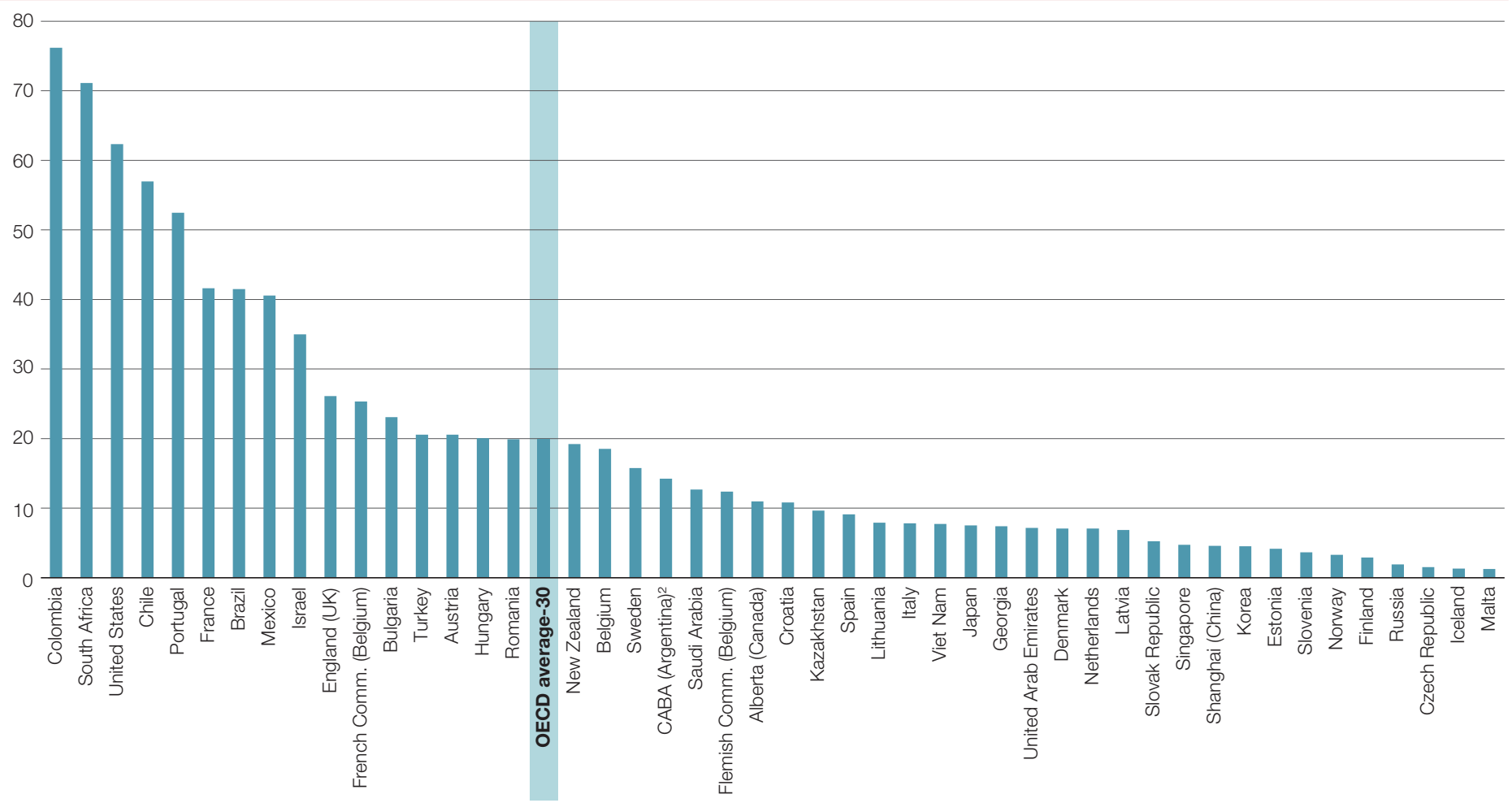

1. "Socio-economically disadvantaged homes" refers to homes lacking the basic necessities or advantages of life, such as adequate housing, nutrition or medical care. 2. Ciudad Autónoma de Buenos Aires is referred to as CABA (Argentina).

Countries and economies are ranked in descending order of the percentage of teachers teaching in schools where more than 30\% of students come from socio-economically disadvantaged backgrounds.

Source: OECD, TALIS 2018 Database, Table I.3.25.

Teachers work with their colleagues aiming to improve instruction, provide specific support to students and for their own professional growth. Collaborative activities are a key part of teachers' non-teaching working time. TALIS 2018 provides rich insights on teachers' collaborative practices in different school contexts. A close look at country-wide patterns of teacher collaboration show that, in some education systems, regular teacher collaboration (i.e. at least once a month) is more prevalent in schools with a high concentration of students from socio-economically disadvantaged backgrounds (Figure 2). For instance, in ten countries and economies participating in TALIS, a higher share of teachers working in these schools regularly engage in teaching jointly as a team in the same class than their peers in schools with lower concentrations of disadvantaged students (Figure 2). The difference ranges from 29 percentage points in Austria to 5 percentage points in Portugal.

Similarly, in eight countries and economies, teachers in challenging schools are more likely to regularly engage in observing other teachers and providing feedback, with the difference ranging from 11 percentage points in England (United Kingdom), to 2 percentage points in Belgium. Taking part in collaborative professional learning and engaging in joint activities across different classes and age groups are more prevalent among teachers working in the schools with a high concentration of disadvantaged students, in seven countries and economies participating in TALIS. The differences range from 15 percentage points in CABA (Argentina), to 3 percentage points in France for participation in collaborative professional learning. 
These findings can be perceived in positive light, suggesting that conditions in challenging school environments can support teacher collaboration. One plausible explanation for these findings can be that challenging school contexts necessitate some form of collaboration because teachers need the knowledge and support of their colleagues to cope with the challenges they face in their work. Additionally, TALIS data show that those countries where collaboration is more prevalent in schools with a high concentration of students from disadvantaged homes have varying shares of teachers - ranging from 5\% to $75 \%$ of their teaching workforce (Figure 1) - working in these challenging schools. Therefore, irrespective of the number of schools with a high concentration of students from socio-economically disadvantaged backgrounds that a country has, the prevalence of teacher collaboration in challenging schools is evident. Further analysis at the country level could help to examine the conditions under which there is support for collaboration in challenging teaching and learning environments.

TALIS groups these four activities under the umbrella of professional collaboration that requires a higher degree of interdependence and co-operation among teachers. Based on the nature of these activities, it is likely that it is specific policies or schools' formal activities in each context that support such collaboration. However, these activities are also more time consuming and, hence, more demanding than simple informal exchanges among teaching colleagues in schools. Education systems should encourage and support such forms of teacher collaboration, as they are aimed directly at improving instructional processes in the classroom.

Figure 2. Differences in teacher collaboration in different school contexts

Based on lower secondary teachers' reports of engagement in the following collaborative activities at least once a month, by concentration of students from socio-economically disadvantaged homes

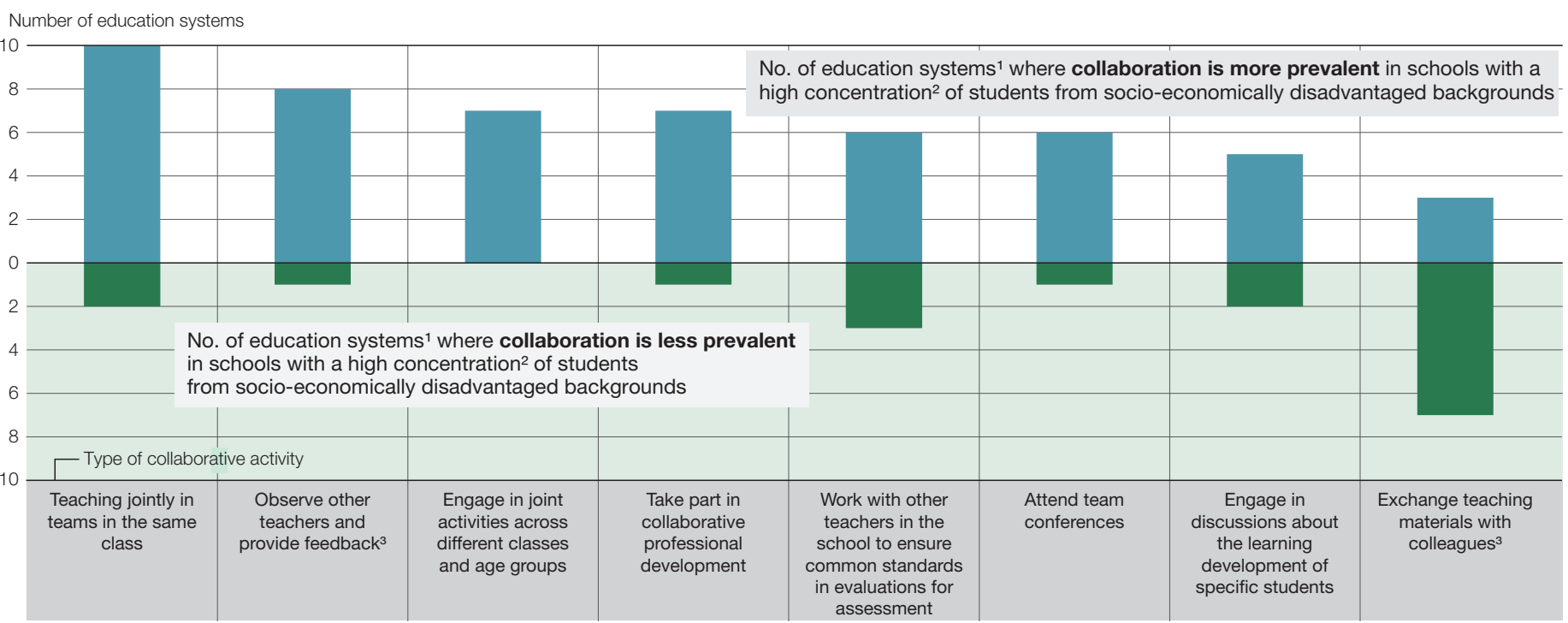

1. Results based on statistically significant findings from the school breakdown data available for 37 countries and economies. Graphical representation excludes country counts for which there is no statistically significant difference between school contexts.

2. Schools with a high concentration of students from disadvantaged homes refers to those with more than $30 \%$ of students from disadvantaged homes.

3. For these two activities, results are based on statistically significant findings from school breakdown data available for 36 countries and economies.

Source: OECD, TALIS 2018 Database; TIF 34, Table 1, www.oecd.org/education/talis/TIF 34 Table1 Collaborative activities teachers.xlsx

In contrast, TALIS findings suggest that exchanging teaching materials with colleagues may be more limited in schools with a high concentration of students from disadvantaged backgrounds. In at least seven countries and economies participating in TALIS, a significantly smaller share of teachers in these schools collaborate in this manner than in schools with lower concentrations of students from disadvantaged backgrounds (Figure 3). This form of collaboration is more natural and may arise from voluntary interactions and interpersonal communication among teachers. Therefore, it may be worth exploring for education systems whether such collaboration is difficult for teachers working in challenging school environments or whether it is simply that, for different reasons, teachers do not find it valuable to collaborate in this manner. 
Figure 3. Exchange of teaching materials with colleagues at least once a month, by school concentration of students from socio-economically disadvantaged homes

Percentage of lower secondary teachers who report that they exchange teaching materials with colleagues at least once a month

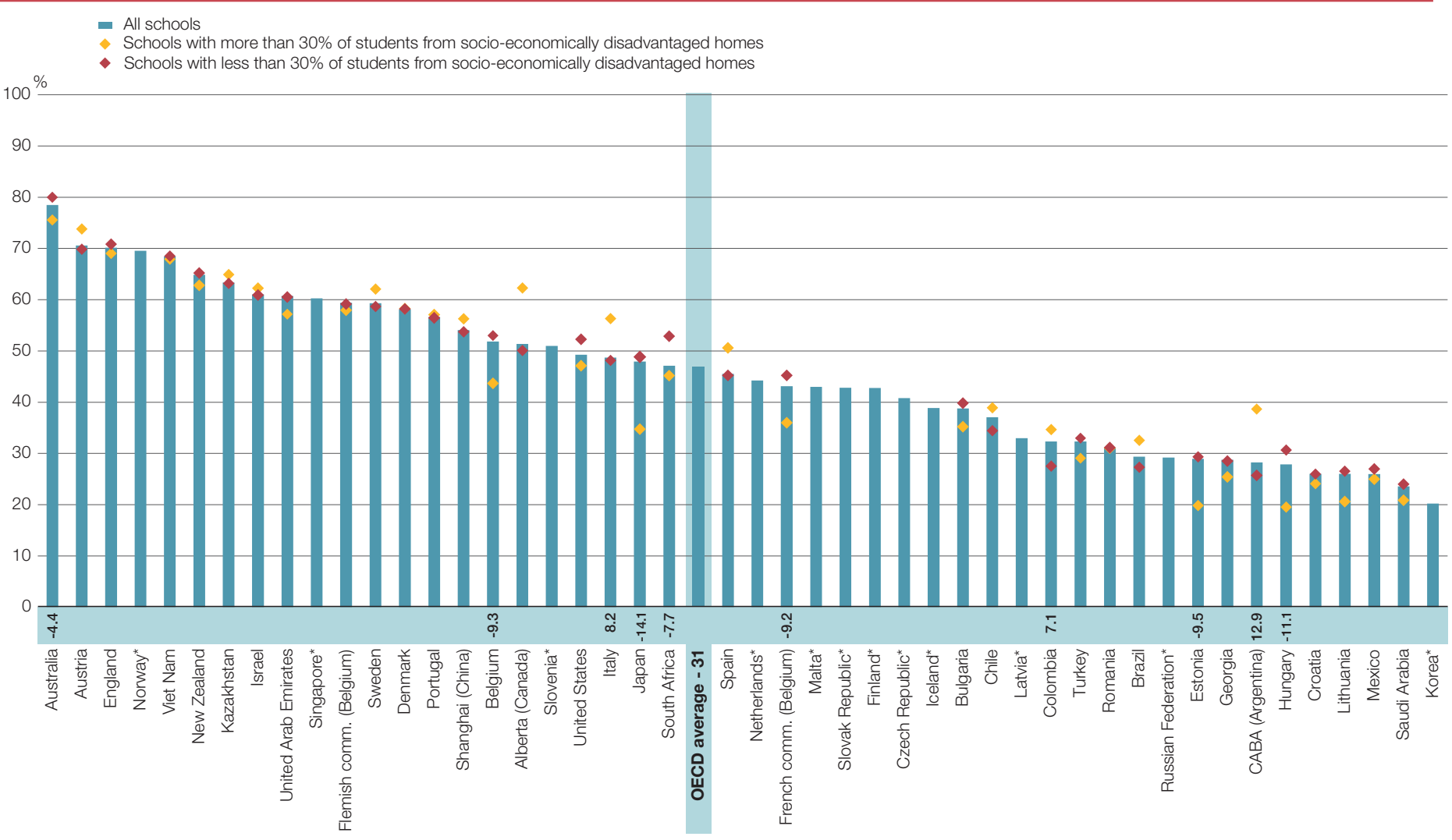

${ }^{*}$ School breakdown results for these countries and economies are not available and, therefore, not shown in this chart.

Note: Statistically significant differences between teachers working in schools with a high concentration of students from socio-economically disadvantaged homes and teachers working in schools with a low concentrations of students from socio-economically disadvantaged homes are shown next to the country/economy name.

Countries and economies are ranked in descending order of the percentage of lower secondary teachers who report that they exchange teaching materials with colleagues at least once a month.

Source: OECD, TALIS 2018 Database; TIF 34, Table 1, www. oecd.org/education/talis/TIF 34 Table1 Collaborative activities teachers.xlsx

Schools with a high concentration of students from socio-economically disadvantaged backgrounds face several challenges: not just lower student achievement and limited resources, but also difficulty in attracting and retaining quality teachers. Professional collaboration among colleagues can act as a support system for teachers facing the various challenges posed by working with students from socio-economically disadvantaged backgrounds. TALIS findings indicate that professional collaboration is associated with higher use of cognitive activation practices in the classroom, such as giving tasks that require students to think critically, or having students work in small groups to come up with a joint solution to a problem. As cognitive activation practices deviate from the traditional lecture mode of instruction and focus on building cross-curricular skills, their use by teachers signals greater innovation (Figure 4). Additionally, TALIS findings also show a positive relationship between professional collaboration and teachers' self-efficacy and satisfaction with their jobs. Therefore, education systems should do more to facilitate teacher collaboration, in particular during the current challenges posed to teaching and learning environments by the COVID-19 crisis. 
Figure 4. Relationship between the use of cognitive activation practices and professional collaboration Change in the index of cognitive activation practices ${ }^{1}$ associated with the index of professional collaboration ${ }^{2,3,4,5}$

Regression coefficient $(\beta)$

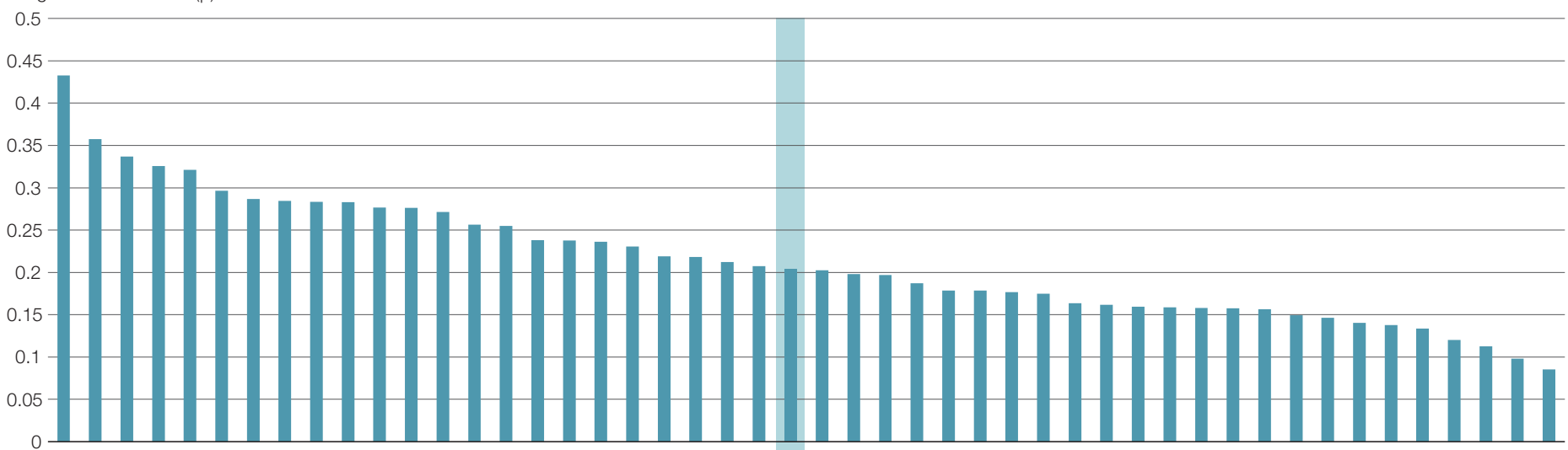

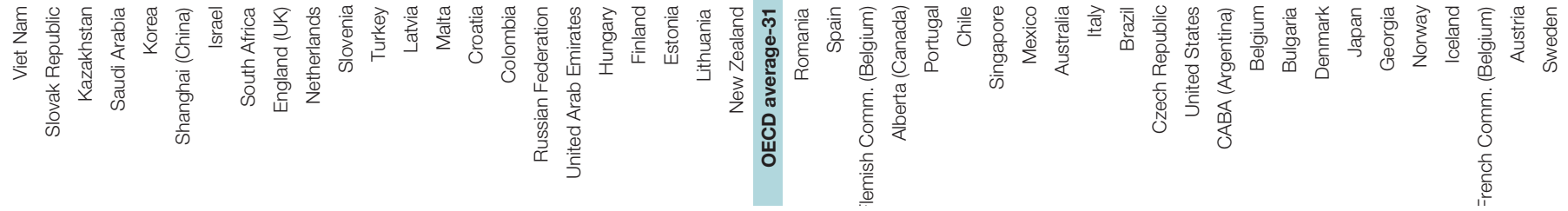

1. The index of cognitive activation practices measures the frequency with which a teacher uses cognitive activation practices in the classroom, including giving tasks that require students to think critically, having students work in small groups to come up with a joint solution to a problem or task, asking students to decide on their own procedures for solving complex tasks and presenting tasks for which there is no obvious solution. These data are reported by teachers and refer to a randomly chosen class they currently teach from their weekly timetable.

2. The index of professional collaboration measures teachers' engagement in deeper forms of collaboration, including teaching jointly as a team in the same class, providing feedback based on classroom observations, engaging in joint activities across different classes and age groups and participating in collaborative professional learning.

3. Results of linear regression based on responses of lower secondary teachers.

4. The analysis is restricted to teachers reporting that their teaching in the target class is not directed entirely or mainly at special needs students.

5. Controlling for the following teacher characteristics: gender, age, years of experience as a teacher at current school and working full-time.

Note: All coefficients shown in this chart are statistically significant.

Countries and economies are ranked in descending order of the change in the index of cognitive activation practices associated with the index of professional collaboration.

Source: OECD, TALIS 2018 Database, Table II.4.13.

\section{The bottom line}

Education systems across the world are facing an enormous challenge to ensure learning continuity in the face of school closures due to the pandemic. Schools with a high concentration of students from socio-economically disadvantaged backgrounds and those that lack adequate teaching and learning resources face an even bigger challenge in providing quality learning experiences for their students. In these times, teacher collaboration needs to be reimagined to meet the current needs and challenges, for example: online professional learning networks, structured online time for co-planning lessons, discussion boards for monitoring students' progress, and creation of question banks for formative online assessments. Supporting teachers so they can work with each other, share resources, keep track of student learning and plan their teaching time efficiently can be one strategy for education systems in addressing new challenges. The findings from TALIS of more frequent collaboration among teachers in schools with a large share of students from socio-economically disadvantaged homes may signal the presence of a culture of collaboration in these schools. This would form a strong foundation to help teachers and schools to overcome the challenges posed by the pandemic. 


\section{Contact}

Aakriti Kalra (Aakriti.kalra@oecd.org) and talis@oecd.org

\section{For more information}

OECD (2020), TALIS 2018 Results (Volume II): Teachers and School Leaders as Valued Professionals, TALIS, OECD Publishing, Paris, https://doi.org/10.1787/19cf08df-en.

The table referred to in this Teaching in Focus brief can be found at: www.oecd.org/education/talis/TIF 34 Table1 Collaborative activities teachers.xlsx

This paper is published under the responsibility of the Secretary-General of the OECD. The opinions expressed and the arguments employed herein do not necessarily reflect the official views of OECD member countries.

This document, as well as any data and map included herein, are without prejudice to the status of or sovereignty over any territory, to the delimitation of international frontiers and boundaries and to the name of any territory, city or area.

The statistical data for Israel are supplied by and under the responsibility of the relevant Israeli authorities. The use of such data by the OECD is without prejudice to the status of the Golan Heights, East Jerusalem and Israeli settlements in the West Bank under the terms of international law.

You can copy, download or print OECD content for your own use, and you can include excerpts from OECD publications, databases and multimedia products in your own documents, presentations, blogs, websites and teaching materials, provided that suitable acknowledgment of OECD as source and copyright owner is given. All requests for commercial use and translation rights should be submitted to rights@oecd.org.

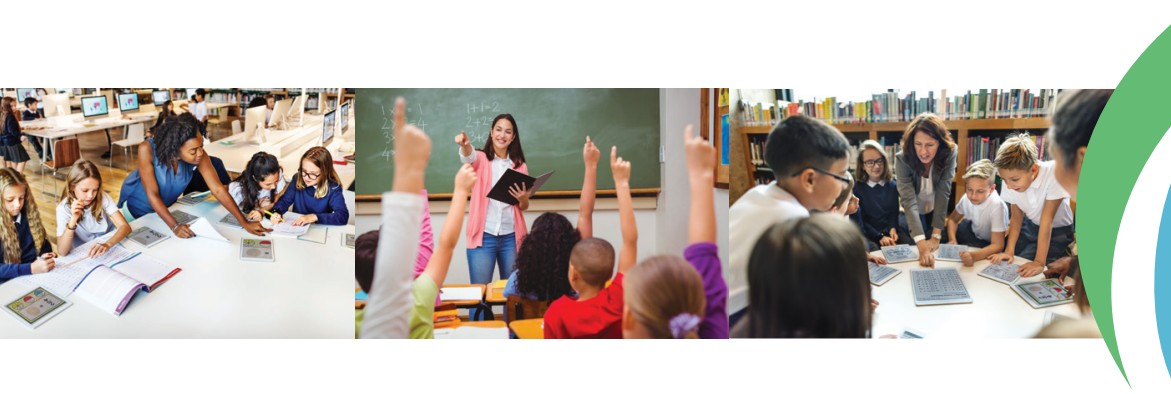

